\title{
Hypothalamic Neurotensin Projections Promote Reward by Enhancing Glutamate Transmission in the VTA
}

\author{
Kimberly A. Kempadoo, ${ }^{1,2}$ Clara Tourino, ${ }^{3}$ Saemi L. Cho, ${ }^{1}$ Francesco Magnani, ${ }^{1}$ Gina-Marie Leinninger, ${ }^{4}$ \\ Garret D. Stuber, ${ }^{1}$ Feng Zhang, ${ }^{3}$ Martin G. Myers, ${ }^{4}$ Karl Deisseroth, ${ }^{3}$ Luis de Lecea, ${ }^{3}$ and Antonello Bonci ${ }^{1,5,6,7}$ \\ ${ }^{1}$ Ernest Gallo Clinic and Research Center, Emeryville, California 94608, ${ }^{2}$ Neuroscience Graduate Program, University of California, San Francisco, California \\ 94158, ${ }^{3}$ Department of Neuroscience, Stanford University, Palo Alto, California 94305, ${ }^{4}$ Department of Neuroscience, University of Michigan, Ann Arbor, \\ Michigan 48105, ${ }^{5}$ Solomon H. Snyder Department of Neuroscience, Johns Hopkins University School of Medicine, Baltimore, Maryland 21205, ${ }^{6}$ Intramural \\ Program, National Institute of Drug Abuse, Baltimore, Maryland 21224, and 7 Department of Neurology, University of California, San Francisco, California \\ 94143
}

The lateral hypothalamus (LH) sends a dense glutamatergic and peptidergic projection to dopamine neurons in the ventral tegmental area (VTA), a cell group known to promote reinforcement and aspects of reward. The role of the LH to VTA projection in reward-seeking behavior can be informed by using optogenetic techniques to dissociate the actions of LH neurons from those of other descending forebrain inputs to the VTA. In the present study, we identify the effect of neurotensin (NT), one of the most abundant peptides in the LH to VTA projection, on excitatory synaptic transmission in the VTA and reward-seeking behavior. Mice displayed robust intracranial self-stimulation of LH to VTA fibers, an operant behavior mediated by NT 1 receptors (Nts1) and NMDA receptors. Whole-cell patch-clamp recordings of VTA dopamine neurons demonstrated that NT (10 nM) potentiated NMDA-mediated EPSCs via Nts1. Results suggest that NT release from the LH into the VTA activates Nts1, thereby potentiating NMDA-mediated EPSCs and promoting reward. The striking behavioral and electrophysiological effects of NT and glutamate highlight the LH to VTA pathway as an important component of reward.

\section{Introduction}

Dopamine release from ventral tegmental area (VTA) neurons promotes motivated, goal-directed behavior (Gallistel et al., 1985; Robinson and Berridge, 2001; Phillips et al., 2003) and is crucial for mediating the reinforcing properties of rewards (Roberts and Koob, 1982; Pontieri et al., 1995; Self et al., 1996; Wise, 2006; Fields et al., 2007; Adamantidis et al., 2011). Glutamatergic synapses onto dopamine neurons undergo synaptic strengthening after exposure to drugs of abuse and natural rewards, a process hypothesized to enhance reward-seeking (Ungless et al., 2001; Borgland et al., 2004; Kauer, 2004; Chen et al., 2008; Bowers et al., 2010; Luscher and Malenka, 2011). Due to previous unavailability of tools to dissect neural circuitry, little is

Received May 29, 2012; revised Feb. 26, 2013; accepted March 4, 2013.

Author contributions: K.A.K., C.T., and A.B. designed research; K.A.K., C.T., S.L.C., and F.M. performed research; G.-M.L., G.D.S., F.Z., M.G.M., K.D., and L.d.L. contributed unpublished reagents/analytic tools; K.A.K. analyzed data; K.A.K. wrote the paper.

This work was supported by the National Institute on Drug Abuse Intramural Research Program, the National Institute of General Medical Sciences, the National Institute of Mental Health, the Klarman Family Foundation, and the State of California. We thank Adrianne Kisch-Hancock for assistance with histology; Howard L. Fields, Stephanie L. Borgland, Viktor Kharazia, and Steven P. Lieske for intellectual discussions regarding this work; and Roy A. Wise for comments on the manuscript.

The authors declare no competing financial interests.

Correspondence should be addressed to Dr. Antonello Bonci, NIDA-IRP, 251 Bayview Boulevard, Room 04A521, Baltimore, MD 21224. E-mail: antonello.bonci@nih.gov.

K.A. Kempadoo's present address: Columbia University, 1051 Riverside Drive, Kolb Annex Unit 87, New York, NY 10032.

A. Bonci's present address: Intramural Research Program, National Institute on Drug Abuse, National Institutes of Health, 9000 Rockville Pike, Bethesda, MD 20892.

DOI:10.1523/JNEUROSCI.2588-12.2013

Copyright $\odot 2013$ the authors $\quad 0270-6474 / 13 / 337618-09 \$ 15.00 / 0$ known about the precise function of VTA afferents arising from various brain regions.

The lateral hypothalamus ( $\mathrm{LH})$ provides an abundant source of glutamatergic and peptidergic input to the VTA and is of particular interest given its role in reward and homeostasis (Kelley et al., 2005; Nestler, 2005; Geisler and Zahm, 2006; Geisler et al., 2007; Adamantidis and de Lecea, 2008). Stimulation of the medial forebrain bundle (MFB) at the level of the LH induces brain stimulation reward and exerts its reinforcing properties via direct or indirect projections to the VTA (Margules and Olds, 1962; Shizgal et al., 1980; Gallistel et al., 1985; You et al., 2001). Conventional electrical stimulation techniques present two major technical limitations that have left the function of the LH to VTA projection ill-defined: (1) electrical stimulation of the $\mathrm{LH}$ also activates the MFB, blurring the distinct role of LH neurons with forebrain fibers of passage; and (2) in vivo electrical stimulation activates entire neural networks, preventing isolation of direct afferents to the VTA.

To elucidate the role of lateral hypothalamic innervation of the VTA in reward-related behavior, we used in vivo and ex vivo optogenetic techniques in mice. We focused on the function of neurotensin (NT), a tridecapeptide found in approximately onethird of VTA-projecting lateral hypothalamic neurons known to interact extensively with dopamine neurons (for review, see Binder et al., 2001) (Carraway and Leeman, 1973; Zahm et al., 2001). Within the VTA, NT increases the firing rate of dopamine neurons (Farkas et al., 1996), increases expression of tyrosine hydroxylase $(\mathrm{TH})$, the rate-limiting enzyme for dopamine synthesis, and promotes dopamine release (Sotty et al., 1998). These 
actions are primarily mediated by the high-affinity NT 1 receptor (Nts1), although signaling also occurs through NT receptors 2 (Nts2) and 3 (Nts3) (Carraway and Leeman, 1973; Farkas et al., 1996; Sotty et al., 1998; Binder et al., 2001). Intra-VTA NT infusion increases locomotor activity, supports conditioned place preference, induces behavioral sensitization, and is actively selfadministered (Kalivas and Taylor, 1985; Elliott and Nemeroff, 1986; Glimcher et al., 1987; Panayi et al., 2005; Rompre and Bauco, 2006). Given that NT promotes these behaviors and enhances forebrain glutamate release (Ferraro et al., 2000; Antonelli et al., 2004; Chen et al., 2006), we investigated the role of NT as a reward peptide that mediates the reinforcing properties of excitatory transmission from the LH to VTA.

\section{Materials and Methods}

Animals and surgery. Adult male C57BL/6J mice were obtained from The Jackson Laboratory and maintained in accordance with the Institutional Animal Care and Use Committee of the Ernest Gallo Clinic and Research Center guidelines. Animals were anesthetized with ketamine/xylazine before the surgical procedure. An adeno-associated virus (AAV, serotype 5) coding for the light-sensitive cation channel, H134R channelrhodopsin-2 (ChR2) and enhanced yellow fluorescent protein (EYFP) under control of the CaMKII promoter were used in this study (from the laboratory of K.D.). For behavioral experiments, the $\operatorname{AAV}(0.3 \mu$ l over $3 \mathrm{~min})$ was injected unilaterally into the rostral lateral hypothalamus (AP, $-0.4 ; \mathrm{ML}, \pm 1.0 ; \mathrm{DV},-4.9$ ) with an ipsilateral $4 \mathrm{~mm}$ guide cannula implanted above the ventral tegmental area (AP, -3.2; $\mathrm{ML}, \pm 0.5 ; \mathrm{DV},-4.0$ ). Bilateral injections were performed to prepare both hemispheres for slice electrophysiology studies. In a subset of experiments, Nts-Cre mice (from the laboratory of M.G.M.) were injected with a doublefloxed virus under control of the EF1 $\alpha$ promoter, enabling specific expression of ChR2 in NT-containing neurons. The laboratory of M.G.M. also generously shared the NT receptor 1 knock-out (NtsR1KO) mouse line. All experiments were conducted at least 3 weeks after surgery.

Pharmacological agents. NT (8-13) was purchased from Sigma-Aldrich; AP5 $(50 \mu \mathrm{M})$ and DNQX $(10 \mu \mathrm{M})$ were obtained from Tocris Bioscience; SR48692 (100 and $500 \mathrm{nM}$ ), the Nts1 receptor antagonist, was ordered through the National Institutes of Mental Health Chemical Synthesis and Drug Supply Program.

Electrophysiology. Horizontal brain slices containing the ventral tegmental area were prepared from C57BL/6J male mice as previously described (Argilli et al., 2008). The brain was rapidly dissected, and horizontal slices ( $200 \mu \mathrm{m}$ thick) containing the VTA were prepared using a Leica vibratome. Slices recovered for at least $45 \mathrm{~min}$ in artificial CSF (aCSF; containing the following in mM: $126 \mathrm{NaCl}, 1.6 \mathrm{KCl}, 2.4 \mathrm{CaCl} 2,1.2$ $\mathrm{NaH}_{2} \mathrm{PO}_{4}, 1.2 \mathrm{MgCl} 2,18 \mathrm{NaHCO} 3$, and 11 glucose, saturated with $95 \%$ $\mathrm{O}_{2}$ and $5 \% \mathrm{CO}_{2}$ ) before being individually transferred to the recording chamber. Slices were superfused with continuous flow $(2 \mathrm{ml} / \mathrm{min})$ aCSF at $32^{\circ} \mathrm{C}$ containing picrotoxin $(100 \mu \mathrm{M})$ to block $\mathrm{GABA}_{\mathrm{A}}$ receptormediated synaptic currents.

Cells were visualized using an upright microscope with infrared illumination. Whole-cell voltage-clamp recordings were made using an Axopatch 1D amplifier (Molecular Devices) with 3-6 M $\Omega$ glass electrodes containing the following (in mM): $120 \mathrm{CsCH} 3 \mathrm{SO} 3,20$ HEPES, 0.4 EGTA, $2.8 \mathrm{NaCl}, 5$ $\mathrm{N}(\mathrm{CH} 2 \mathrm{CH} 3) 4 \mathrm{Cl}, 2.5 \mathrm{Mg}$-ATP, and 0.25 Mg-GTP, pH 7.3. Series resistance (10-30 M $\Omega$ ) and input resistance were monitored on-line with a $4 \mathrm{mV}$ depolarizing step $(50 \mathrm{~ms})$ given just after every afferent stimulus. Putative DA cells were identified by the presence of a large hyperpolarizationactivated potassium current, $\mathrm{I}_{\mathrm{h}}$ (Lacey et al., 1990; Johnson and North, 1992). According to previous studies in mice, TH is present in $~ 98 \%$ of neurons identified by the presence of the $\mathrm{I}_{\mathrm{h}}$ current (Wanat et al., 2008), and there is general agreement that $\mathrm{I}_{\mathrm{h}}(-)$ neurons are not dopaminergic (Margolis et al., 2006). To confirm dopamine neuron identity, a subset of cells were filled with biocytin, fixed overnight with paraformaldehyde (4\%), and post hoc labeled with TH. A bipolar stimulating electrode was placed 100-300 $\mu \mathrm{m}$ rostral to the recorded neuron for electrical experiments. For optical experiments, an optical fiber (multimode, $200 \mu \mathrm{m}$ core diameter, $0.37 \mathrm{NA}$, Thorlabs) coupled to a $473 \mathrm{~nm}$ laser (Laserglow) was aimed at the cell of interest at a distance of 100-200 $\mu \mathrm{m}$. Afferents were stimulated at $0.1 \mathrm{~Hz}$ with pulses of blue light $(430-473 \mathrm{~nm})$ or electric current. Evoked EPSCs were filtered at $2 \mathrm{kHz}$, digitized at 5-10 $\mathrm{kHz}$, and recorded using Igor Pro software (WaveMetrics). Peak evoked AMPA-mediated EPSCs were measured from neurons voltage-clamped at $-70 \mathrm{mV}$. Evoked NMDA-mediated EPSCs were measured $25 \mathrm{~ms}$ after the stimulus artifact in neurons voltage-clamped at $40 \mathrm{mV}$. Statistics were computed between 16-22 min for 30 min electrophysiology experiments and 32-40 min for $50 \mathrm{~min}$ experiments unless otherwise stated. Significance was determined by two-tailed Student's $t$ tests for within-group comparisons to baseline and ANOVA tests (one- or two-way, as appropriate) with Tukey's post hoc analysis for multiple group comparisons. All data shown are the mean \pm SEM.

Optical intracranial self-stimulation. The intracranial self-stimulation (ICSS) paradigm used by Olds and Milner (1954) was adapted by replacing electrical stimulation with optogenetic techniques. A fiber optic cable (Thor Laboratories) attached via FC/PC connector to a $473 \mathrm{~nm}$ laser (blue light, Laserglow) was inserted into and secured to a guide cannula aimed at the VTA. During each $1 \mathrm{~h}$ session, mice explored Med Associates operant boxes containing an active and inactive nosepoke. The inactive nosepoke produced no result. Each active nosepoke delivered a $20 \mathrm{~Hz}$ train of $5 \mathrm{~ms}$ pulses of blue light for $3 \mathrm{~s}$, depolarizing excitatory lateral hypothalamic axons terminating in the VTA. As previously described (Stuber et al., 2011), the active nosepoke was accompanied by a cue light above the nosepoke and a tone $(3 \mathrm{kHz}, 5 \mathrm{~s})$, which were insufficient to promote nosepoking in the absence of optical stimulation. Nosepoke activity was recorded with MedPC software and visually monitored via infrared camera. Animals were limited to $4.5 \mathrm{~g}$ of food per day beginning the day before the first training session to promote apparatus exploration. Mice learned this task within one $60 \mathrm{~min}$ session and were given up to five daily training sessions to reach the 40-600 nosepokes per session criterion. The criterion was set to allow for pharmacological-induced increases and decreases in responding and required the removal of one animal from each group. Animals were assigned to treatment groups a priori. A maximum of two additional sessions were administered to reach steady baseline nosepoke rates preceding drug or vehicle administration. The optical intensity was measured before and after each session to ensure consistent output of $\sim 20 \mathrm{~mW}$. Pharmacological agents $(0.3 \mu \mathrm{l}$ over $3 \mathrm{~min}$ ) were infused into the VTA $10 \mathrm{~min}$ before the session start. AP5 $(0.5 \mu \mathrm{g} / \mathrm{side})$ was obtained from Tocris Bioscience, SR48692 (500 nM) was ordered through the National Institutes of Mental Health Chemical Synthesis and Drug Supply Program, and the vehicle for both drugs consisted of $0.1 \%$ DMSO in saline.

In a separate set of extinction experiments, chronic fiber optic implants were used to deliver light pulses to the VTA. Three $1 \mathrm{~h}$ sessions of each manipulation were averaged to obtain the reported values: (1) extinction: active nosepoke produced cues, but not optical stimulation; (2) reinstatement: optical stimulation was reintroduced without cue presentation; 3) reversal: active nosepoke location was reversed. The nosepoke time stamp was recorded by computer software and used for subsequent analysis of operant behavior. Sessions during which the fiber optic sustained damage were excluded from analysis. Data were analyzed using GraphPad Prism and WaveMetrics IGOR Pro Software. Single asterisks in all figures indicate significant differences $(p<0.05)$.

Immunohistochemistry. For immunohistochemical analysis, animals were perfused with PBS for $5 \mathrm{~min}$, followed by $4 \%$ paraformaldehyde. Brains were dissected, refrigerated at $4^{\circ} \mathrm{C}$ in fixative overnight, and then transferred to $30 \%$ sucrose solution until saturated. Sections $(50 \mu \mathrm{m})$ were prepared on a Leica cryostat (CM3050). Slices were washed with PBS and refrigerated until blocking the tissue with PBT $(0.3 \%$ Triton in PBS) and $10 \%$ normal donkey serum at $25^{\circ} \mathrm{C}$ for $30 \mathrm{~min}$ on a shaker. Slices were incubated at $4^{\circ} \mathrm{C}$ for $16 \mathrm{~h}$ with 1:100 rabbit anti-TH (Millipore Bioscience Research Reagents), then washed and blocked with $2 \%$ normal donkey serum before incubating in Alexa-594 donkey anti-rabbit secondary antibody (Invitrogen). Finally, slices were incubated for $1 \mathrm{~h}$ at $25^{\circ} \mathrm{C}$ in 1:100 neurotrace (Invitrogen) in PBS, then washed, mounted, and visualized with a Nikon E600 inverted microscope and a Zeiss LSM 510 META confocal microscope. 
A

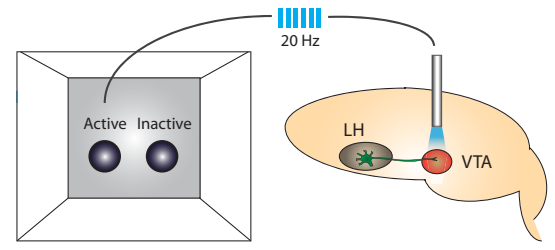

B
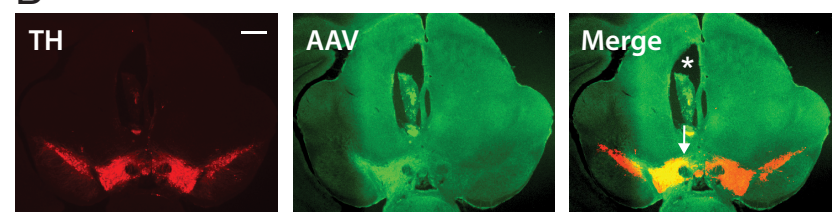

C
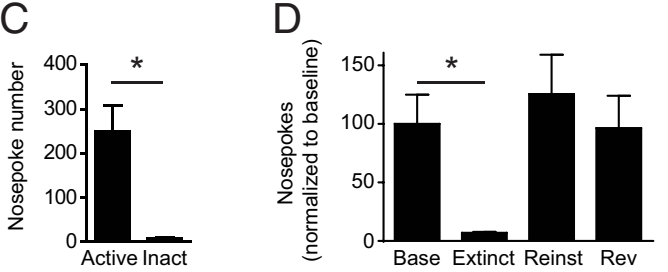

Figure 1. A, Schematic of the optical ICSS paradigm. Each active nosepoke produced a train of $20 \mathrm{~Hz}$ blue light pulses ( 5 ms each) to stimulate lateral hypothalamic axons terminating in the VTA. $\boldsymbol{B}$, Images showing cannula placement aimed at the VTA. TH (red) indicates midbrain dopamine neurons; green represents (hR2-expressing neurons (AAV). In the merged image: *The cannula location. The arrow indicates cannula path toward the VTA. Scale bar, $500 \mu \mathrm{m}$. C, Average nosepoke rates for optical stimulation of LH to VTA fibers. Mice perform significantly more active nosepokes (black) than inactive nosepokes (white) ( $p<0.001, n=10$, MannWhitney test). $\boldsymbol{D}$, Extinction experiment depicting operant responding at the active nosepoke. Base, Baseline session to which active nosepokes were normalized; Extinct, extinction experiments in which the laser was turned off 10 min into the hour-long trial, nosepoke cues remained present; Reinst, reinstatement sessions in which each active nosepoke produced optical stimulation in the absence of nosepoke cues; Rev, reversal experiments during which the active and inactive nosepokes were switched. Active nosepokes during extinction, but not reinstatement or reversal, were significantly lower than baseline ( $p=0.006, n=10$, Dunnett's multiplecomparisons test).

\section{Results}

\section{Activation of LH to VTA fibers reinforces}

behavioral responding

We modified the conventional model of electrical ICSS by optogenetically stimulating LH fibers in the VTA (Fig. 1A). We first confirmed that VTA dopamine neurons, indicated by TH immunoreactivity in Figure $1 B$, were surrounded by a dense network of lateral hypothalamic axons expressing ChR2. Animals produced robust optical ICSS of LH to VTA fibers (Fig. 1C,D). On average, animals nosepoked for optical ICSS $229 \pm 63$ times within the hour-long baseline session and only produced $9 \pm 2$ nosepokes at the inactive nosepoke ( $n=10$, Fig. $1 C)$. In all tested groups, active nosepokes were significantly greater than inactive nosepokes with no significant difference in nosepoke number during baseline and vehicle sessions (data not shown).

To determine whether operant responses were performed for the rewarding effects of optical stimulation or for cue presentation, a separate group of extinction experiments were conducted. During extinction sessions in which active nosepokes produced cues, but not optical stimulation, operant responding was reduced to $6.2 \pm 0.8 \%$ of baseline responding. Reintroduction of optical stimulation in the absence of cues reinstated operant responding at the active nosepoke (125.5 $\pm 33.5 \%$ of baseline) and responding was successfully transferred upon reversal of the active nosepoke position $(96.3 \pm 27.7 \%$ of baseline, one-way ANOVA, Dunnett's multiple-comparisons test, treatment:
$F_{(1.069,9.620)}=11.72, n=10, p=0.006$; Fig. $\left.1 D\right)$. Since baseline responding was higher in the chronic fiber-implanted extinction group than the cannula-implanted pharmacological groups presented in Fig. $1 C$, we graphed normalized active nosepoke values to facilitate comparison (Fig. 1D). Raw values are as follows: baseline, active $=689.5 \pm 173.1$, inactive $=$ $24.3 \pm 8.2$; extinction, active $=47.1 \pm 5.2$, inactive $=7.4 \pm 1.6$; reinstatement, active $=865.6 \pm 231.4$, inactive $=6.1 \pm 1.2$; reversal, active $=664.5 \pm 191.2$, inactive $=29.1 \pm 2.2$. Together, these experiments support the hypothesis that optical self-stimulation of LH to VTA synapses is rewarding.

\section{Blockade of endogenous NT in the VTA attenuates self-stimulation of LH to VTA fibers}

Given reports that rats self-administer NT into the VTA (Glimcher et al., 1987), we sought to determine whether NT is implicated in LH to VTA ICSS. NT binds to four known receptors (Nts1-Nts4); however, its action at the high-affinity Nts1 receptor is thought to drive the majority of NT-induced behaviors (Vincent et al., 1999; Caceda et al., 2005; Felszeghy et al., 2007). We tested the effect of an intra-VTA infusion of Nts1 antagonist SR48692 (500 nM) on optical ICSS. The main effect of the drug was significantly greater at the active nosepoke than at the inactive nosepoke (SR48692, $n=5: 116 \pm 37$ active, $9 \pm 3$ inactive; vehicle, $n=3: 393 \pm 155$ active, $12 \pm 2$ inactive; drug $F_{(1,12)}=5.13, p=0.043$; nosepoke type $F_{(1,12)}=15.57, p=0.002$; interaction $F_{(1,12)}=4.90, p=$ 0.047 ). The drug effects are as follows: active nosepoke, $p<0.05$; inactive nosepoke, $p>0.05$ (two-way ANOVA, Bonferroni post hoc test; Fig. 2A). Nts1 antagonist-treated animals also showed a lower percentage of nosepokes than vehicle-treated animals (SR 48692: $33.0 \pm 9.3 \%$ baseline; vehicle: $99.0 \pm 19.6 \%$ baseline; $p=0.036$, Mann-Whitney test; Fig. 2A). The vehicle control group confirmed that repeated intra-VTA infusion did not alter baseline nosepoke activity (one-way ANOVA, treatment: $\left.F_{(1.092,2.184)}=0.073, p=0.830\right)$. Although previous studies have investigated the effect of NT infusion in the VTA (Kalivas and Taylor, 1985), this is the first demonstration that endogenous signaling at Nts1 is critical for modulating the operant behavior produced by specific activation of LH to VTA fibers.

To determine whether the pattern of nosepoking was altered in the presence of SR48692, we plotted the cumulative number of nosepokes for vehicle and Nts1 antagonist sessions (Fig. 2B, example animal). A histogram of the internosepoke intervals reveals a bimodal distribution (vehicle coefficient of bimodality $=0.880$ ), indicating distinct periods of continuous nosepoking punctuated by long pauses (Fig. $2 \mathrm{C}$ ). We therefore defined a bout, or cluster of higher-rate nosepoke activity, as a series of three or more nosepokes with an internosepoke interval $<30 \mathrm{~s}$. The interval histogram shows a lower frequency of short internosepoke intervals in the Nts1 antagonist condition (red) versus the vehicle condition (blue). This suggests that antagonisttreated animals spent less time performing high-frequency nosepokes. The raster plots in Figure 2, $D$ and $E$, illustrate a notable difference in bout activity in the absence of NT signaling. The number of bouts, bout duration, and number of nosepokes per bout were marginally, but not significantly, lower during SR48692 trials ( $p=0.396, p=0.111$, and $p=0.111$, respectively, Mann-Whitney test). Antagonist-infused animals did not display altered motor behavior. The preservation of intrabout nosepoke frequency served as a motor control, demonstrating that animals were physically capable of nosepoking at the same rate whether infused with SR48692 or vehicle ( $p=1.000$, MannWhitney test; data not shown). No alterations in motor behavior 

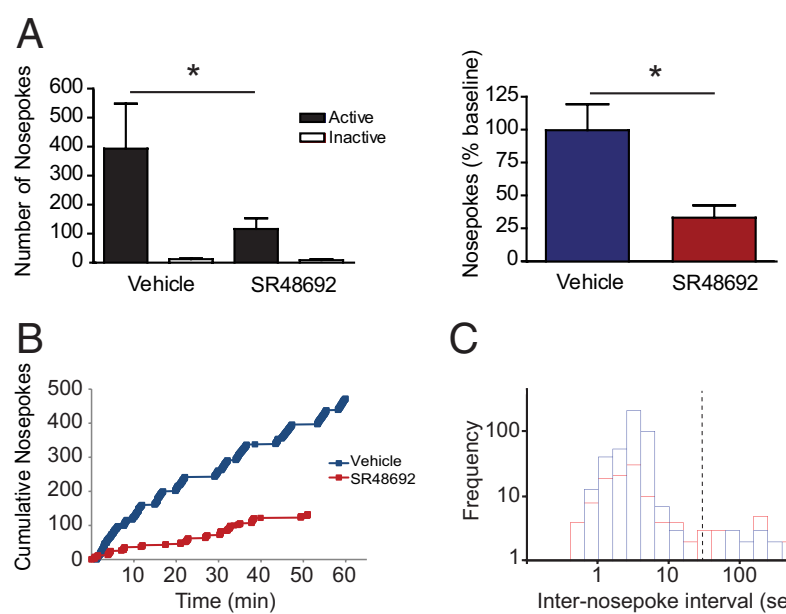

C
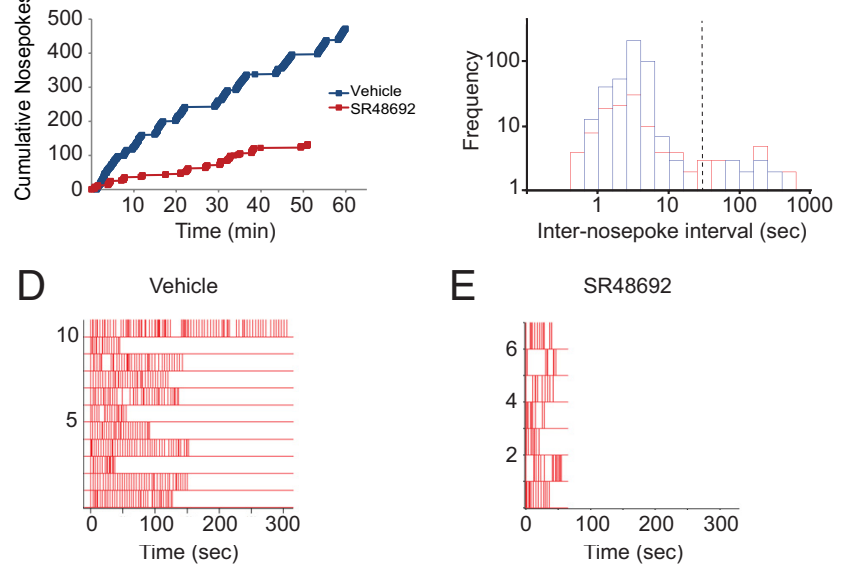

Figure 2. A, SR48692 reduced optical self-stimulation of LH to VTA fibers. Day 1, baseline; Day 2, vehicle (0.1\% DMS0 in saline); Day 3, SR48692, the Nts 1 antagonist. Left, Raw nosepoke data. SR48692, $n=5: 116 \pm 37$ active, $9 \pm 3$ inactive; vehicle, $n=3: 393 \pm 155$ active, $12 \pm$ 2 inactive ( $p<0.05$ active nosepoke comparison; $p>0.05$ inactive nosepoke comparison; two-way ANOVA, Bonferroni post hoc test). Right, Normalized active nosepokes. SR48692, $33.0 \pm 9.3 \%$ baseline; vehicle, $99.0 \pm 19.6 \%$ baseline ( $p=0.036$, Mann-Whitney test). $\boldsymbol{B}$, Cumulative nosepokes of a representative mouse after infusion of vehicle (blue) and SR48692 (red), the Nts1 receptor antagonist. Each square represents one nosepoke. C, Frequency distribution of internosepoke intervals. Blue represents vehicle; and red, Nts1 antagonist. The $30 \mathrm{~s}$ internosepoke interval (hyphenated line) separates the bimodal distribution into high- and low-frequency nosepoking. Bout, three or more nosepokes with and interpoke-interval $<30$ s. $\boldsymbol{D}, \boldsymbol{E}$, Raster plots of bout activity from the representative animal. Each red tick represents one nosepoke; each line is one bout within a given session.

were observed in the antagonist group. Together, the Nts1 antagonist reduced the number of nosepokes per bout, the length of each bout, and the overall number of bouts, to yield a significantly lower number of nosepokes per session.

\section{NMDA receptor signaling in the VTA promotes self-stimulation of LH to VTA fibers}

NMDA receptors are required for certain forms of burst firing in dopamine neurons and are critical for the development of synaptic plasticity in the VTA (Bonci and Malenka, 1999; Ungless et al., 2001; Zweifel et al., 2008). To identify whether glutamate signaling at the NMDA receptor is important for LH to VTA optical self-stimulation, the NMDA receptor antagonist, AP5, was infused into the VTA before the ICSS session. Compared with vehicle, AP5 significantly reduced the number of active nosepokes (AP5, $n=4: 48 \pm 19$ active, $7 \pm 4$ inactive; vehicle, $n=4: 290 \pm$ 104 active, $14 \pm 6$ inactive; drug, $F_{(1,12)}=5.64, p=0.035$; nosepoke type, $F_{(1,12)}=9.04, p=0.011$; interaction, $F_{(1,12)}=4.97$, $p=0.046$; drug effect, active nosepoke, $p<0.05$; inactive nosepoke, $p>0.05$; two-way ANOVA, Bonferroni post hoc test) (Fig. $3)$ as well as the percentage of nosepoking $(11.1 \pm 3.7 \%, n=4$, Mann-Whitney test, $p=0.029$ compared with vehicle) and did not impair the ability of the rodent to explore the operant chamber or physically perform a nosepoke (Fig. 3). This indicates that

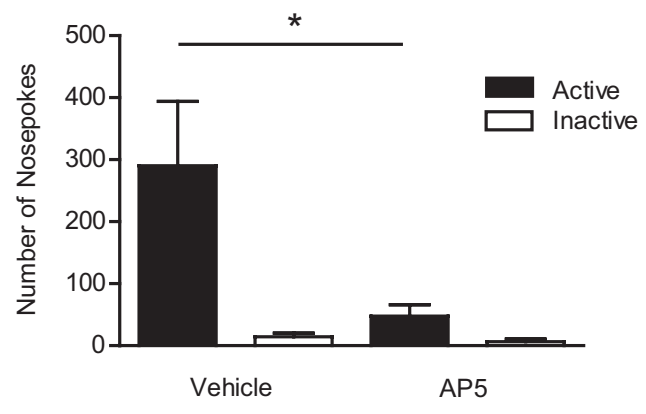

Figure 3. AP5 reduces optical self-stimulation of $L H$ to VTA fibers. Using a between-subject design, animals received either AP5, the NMDA receptor antagonist, or vehicle before the optical ICSS session. Groups did not differ in baseline operant responding. AP5, $n=4: 48 \pm 19$ active, $7 \pm 4$ inactive; vehicle, $n=4: 290 \pm 104$ active, $14 \pm 6$ inactive; $p=0.035$; two-way ANOVA, Bonferroni post hoc test.

NT and glutamate release from the LH to the VTA promotes nosepoking behavior via Nts1 and NMDA receptor activation.

\section{NT has bidirectional effects on NMDA-mediated EPSCs}

Given that NT and glutamate in the VTA supported optical ICSS and given the ability of Nts1 and NMDA receptors to interact with one another (Antonelli et al., 2004), we next identified the effect of NT on excitatory transmission onto VTA dopamine neurons. Ten minute bath application of NT (10 nM) produced a $19.2 \pm 1.3 \%$ increase in NMDA-mediated EPSCs in VTA dopamine neurons $(n=6, p<0.001$; Fig. $4 A, C, E)$. At higher concentrations $(100-500 \mathrm{nM})$, NT produced a reduction in NMDA current that persisted after washout ( $100 \mathrm{nM}: 85.1 \pm 2.2 \%, n=5$, $p<0.001 ; 300$ nм: $66.6 \pm 4.5 \%, n=5, p<0.001 ; 500$ nм: $77.7 \pm$ $1.2 \%, n=5, p<0.001$, pre-drug vs post-drug exposure; Fig. $4 B, D, E)$. Example traces of NT-induced potentiation and reduction of NMDA current are shown in Figure $4 F$.

The Nts1 antagonist, SR48692 (100 nM), blocked NT-induced potentiation of NMDA currents $(n=5, p=0.028$; Fig. $5 A)$. Interestingly, SR48692 (500 nM) attenuated, but did not eliminate, the NMDA current reduction induced by $100 \mathrm{nM}$ NT (NT $100 \mathrm{~nm}$ and SR48692 $500 \mathrm{~nm}$ : $89.7 \pm 0.9 \%, n=8, p<0.001$; Fig. $5 B)$. We established that SR48692 had no effect on evoked EPSCs when administered alone $(n=9, p=0.963)$. Therefore, NT ( 10 $\mathrm{nM}$ ) binding at Nts1 enhanced signaling at the NMDA receptor, while higher concentrations of the peptide reduced NMDAmediated current via Nts1 and another unidentified receptor.

To expand upon antagonist experiments, we studied the Nts1 knock-out mouse (NtsR1KO). In agreement with antagonist studies, NT-induced potentiation was not observed in the absence of Nts1 compared to wild-type controls. The NT-induced reduction at higher concentrations remained present in NtsR1KO mice (Fig. 5C,D).

\section{NT reduces AMPA-mediated EPSCs}

We next examined the effect of NT on AMPA-mediated EPSCs recorded at $-70 \mathrm{mV}$ and found that NT reduced AMPA current in a dose-dependent manner (Fig. 6A-C). The NT-induced reduction is not due to Nts1 signaling, as SR48692 did not block NT suppression of AMPA-mediated EPSCs (Fig. 6D). NT also lowered AMPA current amplitude at a holding potential of $40 \mathrm{mV}$ in the presence of AP5 (Fig. 6E). This suggests that the NT effect is independent of electrochemical driving force and therefore unlikely due to an indirect effect. Paired-pulse ratio experiments were conducted to investigate whether this reduction was presyn- 
A

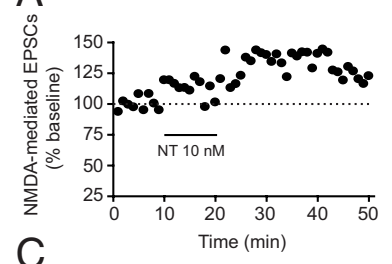

$\mathrm{C}$

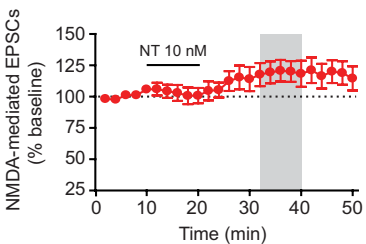

$\mathrm{E}$

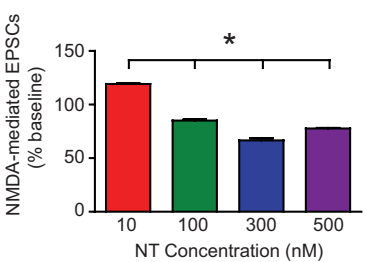

B

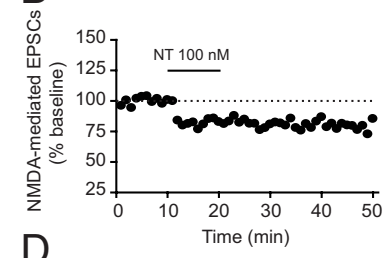

D

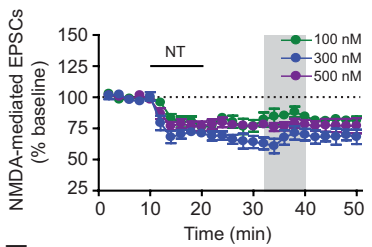

F

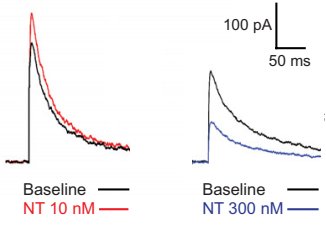

Figure 4. $A, B$, Single-cell examples of evoked NMDA-mediated current in a VTA neuron recorded via whole-cell, voltage-clamp experiments at a holding potential of $40 \mathrm{mV}$. NMDA currents were measured $25 \mathrm{~ms}$ after the stimulus artifact. The NT active peptide fragment (8-13) was bath applied for $10 \mathrm{~min}$ before being washed out. A, NT 10 nм. B, 100 nм. C, $D$, Population responses to varied doses of NT. $C, 10 \mathrm{~nm}$ (red): $119.2 \pm 1.3 \%, n=6, p<0.001$. D, 100 пм (green): $85.1 \pm 2.2 \%, n=5, p<0.001 ; 300$ nм (blue): $66.6 \pm 4.5 \%, n=5, p<$ $0.001 ; 500 \mathrm{~nm}$ (purple): $77.7 \pm 1.2 \%, n=5, p<0.001$. The shaded regions indicate the data points averaged for analysis. $\boldsymbol{E}$, Average dose-responses of NMDA-mediated current to NT. One-way ANOVA with Tukey's post hoc analysis indicated that all concentrations were significantly different from one another $(p<0.001$ for all comparisons, except 100 vs $500 \mathrm{~nm}$ in which $p<0.01) . \boldsymbol{F}$, Example traces of NT-induced potentiation at $10 \mathrm{~nm}$ (red) and inhibition by $300 \mathrm{~nm}$ NT (blue). Approximately 12 sweeps were averaged per trace. The stimulus artifacts were removed from the trace examples.

aptic or postsynaptic; however, results were not significant and therefore insufficient to rule out either locus of action (Fig. $6 F$ ). The NT-induced depression of AMPA current was also observed in NtsR1KO mice (Fig. 6G,H).

\section{NT (10 nM) has a net excitatory effect on VTA EPSCs}

The $10 \mathrm{~nm}$ concentration of NT exerted opposing effects on NMDA and AMPA currents, which raised the question of the net effect of NT on the combined EPSC. We measured the EPSC $\sim 2.5 \mathrm{~ms}$ after the stimulus artifact, a time point at which glutamatergic EPSCs are carried by both AMPA- and NMDAmediated components (Fig. 7A). NT potentiated the combined EPSC (Fig. $7 B, D, F$ ), revealing that the overall effect of NT on the glutamate current is excitatory. We then compared the early time point of the EPSC with the late-phase component mediated solely by the NMDA receptor (25 ms after the stimulus artifact, Fig. $7 C, E)$. The combined EPSC increased significantly less than the isolated NMDA current in the same neurons, suggesting that the AMPA-mediated, early phase component of the EPSC was reduced (Fig. 7B). Indeed, we found that AMPA-mediated currents recorded at $40 \mathrm{mV}$ in the presence of AP5 were reduced by NT (Fig. 6E). However, the NT-induced reduction of the AMPA component was overshadowed by potentiation of NMDAmediated current (NMDA, $123.4 \pm 5.2$; combined EPSC, $116.4 \pm 3.5 \%, n=8, p=0.037$; Fig. $7 B-F)$.
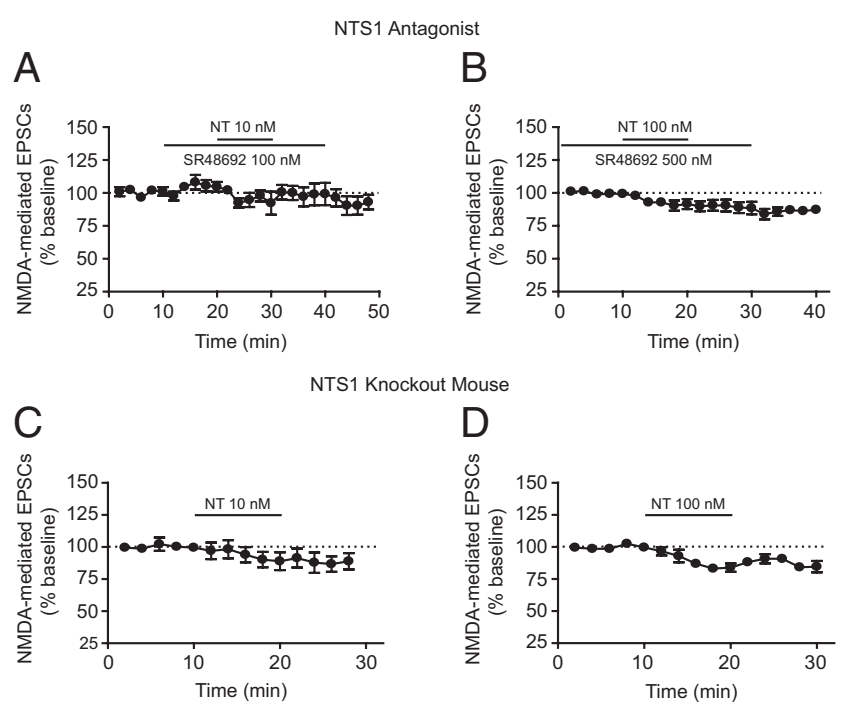

Figure 5. $\quad \boldsymbol{A}, \boldsymbol{B}$, The Nts 1 antagonist, SR48692, was bath applied 10 min before and washed out $10 \mathrm{~min}$ after NT superfusion. Antagonist concentrations were higher than those of the agonist in each experiment to ensure receptor occupancy by the antagonist. $A, S R 48692100 \mathrm{~nm}$ blocked NT-induced potentiation at $10 \mathrm{~nm}(99.2 \pm 1.3 \%, n=5, p=0.028$ measured $12 \mathrm{~min}$ after NT application). $\boldsymbol{B}$, SR48692 $500 \mathrm{~nm}$ attenuated NT-induced reduction at $100 \mathrm{~nm}$ (89.7 \pm $0.9 \%, n=8, p<0.001)$. Comparisons were conducted between minutes 16 and 22 . C, $\boldsymbol{D}$, Effect of NT on NMDA-mediated EPSCs in Nts1 knock-out mice. C, $10 \mathrm{~nm}(91.1 \pm 2.2 \%, n=7, p=$ 0.006 compared with the effect of NT $10 \mathrm{~nm}$ in wild-type). $D, 100 \mathrm{~nm}(85.6 \pm 2.4 \%, n=4, p=$ 0.008 compared with the effect of NT $100 \mathrm{~nm}$ in wild-type). Analysis was conducted between minutes 16 and 22 .

\section{Endogenous NT is present at LH to VTA synapses}

Given that NT is predominantly released from lateral hypothalamic fibers terminating in the VTA (Geisler and Zahm, 2006), we next asked whether NT exerts differential effects at LH to VTA synapses versus nonspecific, electrically stimulated synapses. Optogenetic techniques were used to selectively activate lateral hypothalamic fibers forming synapses onto VTA dopamine neurons while unidentified glutamatergic afferents were electrically stimulated. The AAV coding for channelrhodopsin-2 under control of the CaMKII promoter successfully infected neurons in the lateral hypothalamus and resulted in expression of ChR2 in axonal fibers extending into the VTA (Fig. $8 A, B$ ). A horizontal hemisection of the mouse brain ( $50 \mu \mathrm{m}$ thick) shows the rostral $\mathrm{LH}$ site of AAV injection in the green ChR2-EYFP panel with notable projections to the VTA. The red channel depicts neurons positive for $\mathrm{TH}$ immunoreactivity in the ventral tegmental area and the substantia nigra. The merged inset illustrates that a dense network of ChR2 axons entangle dopamine neurons (Fig. $8 B$ ). This optically isolated pathway is excitatory given that a $5 \mathrm{~ms}$ pulse of blue light aimed at the VTA excited lateral hypothalamic fibers and produced both AMPA- and NMDAmediated EPSCs in VTA dopamine neurons (Fig. 8B).

Given the pronounced NT-induced potentiation of electrically evoked current, we hypothesized that NT would have a greater effect at LH to VTA synapses as a result of either higher Nts1 density or an abundance of endogenously released NT. Surprisingly, we observed the opposite. NT (10 nM) decreased optically evoked NMDA current in the VTA $(70.1 \pm 6.1 \%, n=6, p<$ 0.001 ; Fig. $8 C, D)$. To verify that this effect was not due to recording from two distinct neuronal populations, the experiment was repeated by activating the recorded neuron with alternating electrical and optical signals. One pulse of electrical current, then one pulse of blue light, was repeatedly applied in the VTA 100-200 
A

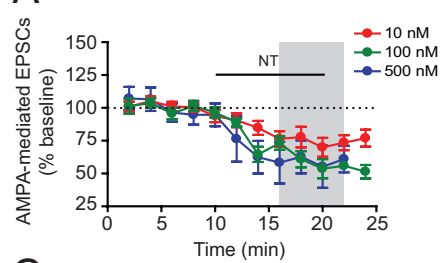

C

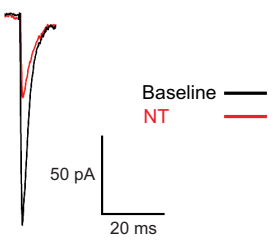

E

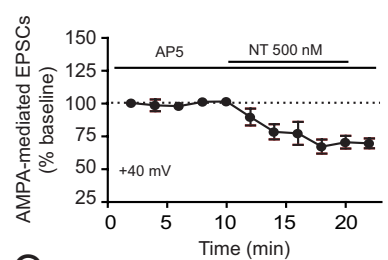

G

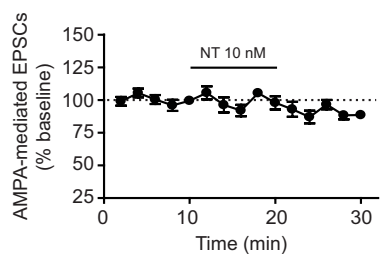

B

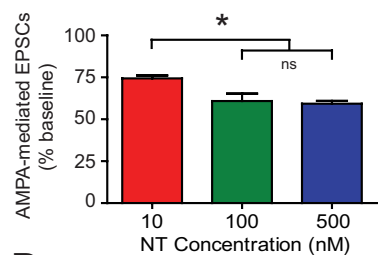

D

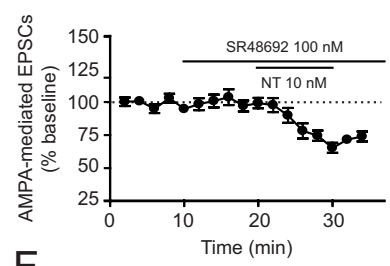

$\mathrm{F}$

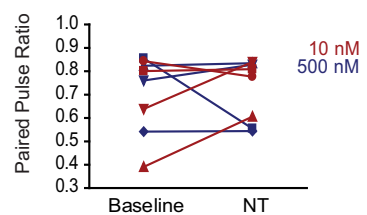

$\mathrm{H}$

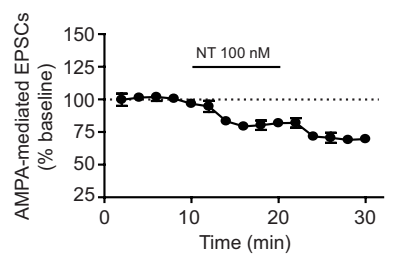

A

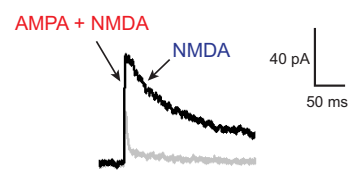

C

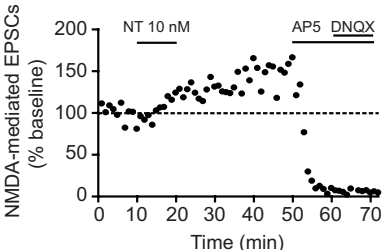

E

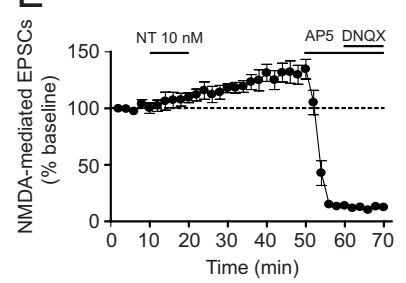

B

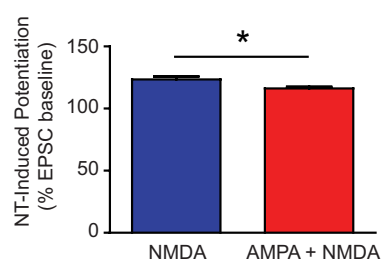

D

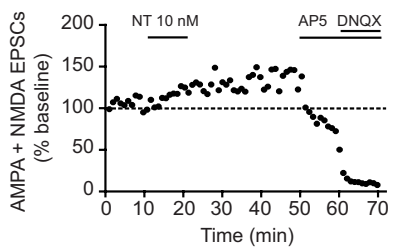

F

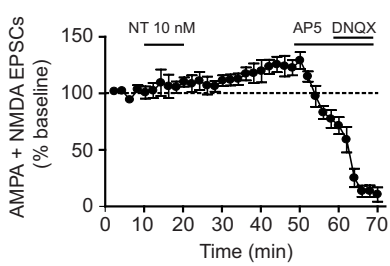

Figure 7. A, Illustration demonstrates that the current carried by both the AMPA and NMDA receptors, the early- and late-phase components of the EPSC, respectively, was measured 2.5 ms after the stimulus artifact. The NMDA component alone was measured $25 \mathrm{~ms}$ after the stimulus artifact (black). The AMPA-mediated current revealed by bath application of NMDA antagonist AP5 decays quickly (gray). Analysis was conducted between minutes 32 and 40 for all panels. $\boldsymbol{B}$, Bar graph plotting average values of potentiation measured at the two points shown in $\boldsymbol{A}$. NMDA $=123.4 \pm 5.2 \%, \mathrm{AMPA}+\mathrm{NMDA}=116.4 \pm 3.5 \% ; n=8, p=0.037$. C, $D$, Raw data, single-cell responses to AP5 (50 $\mu \mathrm{m})$, NMDAR antagonist, and DNQX (10 $\mu \mathrm{m})$, AMPAR antagonist when measured at different time points. $\boldsymbol{E}, \boldsymbol{F}$, NT response in a population of VTA dopamine neurons. $\boldsymbol{E}$, NMDA only $(123.4 \pm 5.2 \%)$. $\boldsymbol{F}$, Combined AMPA + NMDA peak $(116.4 \pm 3.5 \%) ; n=8$.

ANOVA indicated that the treatment was a significant factor $(p=0.009)$. Tukey's post ho analysis revealed that the $10 \mathrm{~nm}$ effect was significantly different from both 100 and $500 \mathrm{~nm}$ $(p<0.05)$; however, 100 and $500 \mathrm{~nm}$ were not statistically different from one another $(p>$ 0.05). Average values were determined between minutes $16-22$ for $\boldsymbol{A}, \boldsymbol{D}, \boldsymbol{E}, \boldsymbol{G}$, and $\boldsymbol{H}$, as indicated by the shaded region. $C$, Response of a single neuron to electrical stimulation in the absence (black) and presence (red) of $10 \mathrm{~nm}$ NT. The stimulus artifact was removed from the trace example. D, SR48692, the Nts1 antagonist, was bath applied before, during, and after NT application. AMPA-mediated current reduction of $72.5 \pm 5.4 \% ; n=5$ was not statistically distinct from the $74.4 \pm 3.5 \%$ current reduction observed by $10 \mathrm{~nm}$ NT in the absence of the antagonist $(p=0.570)$. $\boldsymbol{E}$, AMPA-mediated currents were recorded at a holding potential of $40 \mathrm{mV}$ in the presence of NMDA-receptor antagonist, AP5 $(71.2 \pm 4.3 \%, n=6, p<0.001$ from baseline, $p=0.310$ vs AMPA-mediated currents recorded at $-70 \mathrm{mV}$ ). $\boldsymbol{F}$, Paired-pulse ratios of two AMPA EPSC peaks evoked $50 \mathrm{~ms}$ apart at a holding potential of $-70 \mathrm{mV}$. Red represents cells perfused with $10 \mathrm{~nm} \mathrm{NT}$; blue, $100 \mathrm{~nm}$ (no significant difference, $p=0.631$ and $p=0.475$, respectively). $\mathbf{G}, \boldsymbol{H}$, Effect of NT on AMPA-mediated EPSCs in NT 1 receptor knock-out mice. $\boldsymbol{G}, 10 \mathrm{~nm}(97.1 \pm 6.1 \%, n=5, p=0.114$ from baseline, $p<0.001$ compared with the effect of NT $10 \mathrm{~nm}$ in wild-type). $\boldsymbol{H}, 100 \mathrm{~nm}(80.9 \pm 1.3 \%, n=4, p<0.001$ from baseline, $p=$ 0.068 compared with effect of NT $100 \mathrm{~nm}$ in wild-type).

$\mu \mathrm{m}$ from the cell body at $0.1 \mathrm{~Hz}$. Within the same neuron, NT (10 nM) concomitantly potentiated electrically evoked NMDA current and reduced current at optically stimulated LH to VTA synapses $(n=8, p<0.001$; Fig. $8 E, F)$.

One possible explanation for this divergent effect is that NT is released at LH to VTA synapses, such that the addition of NT (10 $\mathrm{nM})$ by bath application reproduces the EPSC inhibition observed at high NT concentrations (e.g., Fig. $4 B, D$ ). To test this hypothesis, we used the Cre-lox system to selectively activate LH neurons containing NT. A double-floxed AAV coding for ChR2 was injected into the LH of Nts-Cre mice enabling translation of

the light-sensitive channel only in Cre-expressing NT neurons. Optical stimulation of lateral hypothalamic, NT-containing synaptic boutons generated NMDA-mediated currents in the VTA (Fig. 9A). The $\mathrm{GABA}_{\mathrm{A}}$ antagonism in this study suggests that a population of excitatory NT neurons send a direct projection from the LH to the VTA. If NT is indeed released at lateral hypothalamic NT to VTA synapses, then the Nts1 antagonist would eliminate the NT contribution to the baseline NMDA-mediated current. In agreement with our hypothesis, we observed that SR48692 (500 nM) lowered optically evoked NMDA-mediated EPSCs (Fig. 9A), suggesting that the NT peptide was actively released at LH to VTA synapses. The antagonist had no effect on electrically evoked current, confirming that electrically activated glutamatergic axons did not release NT and that the antagonist has no effect on its own. Together, these electrophysiological results indicate that NT is present at LH to VTA synapses and Nts1 signaling potentiates NMDA-mediated current in the VTA.

\section{Discussion}

Our data demonstrate that optical self-stimulation of the direct projection from the LH to the VTA is mediated by NT and glutamate. Using optogenetic techniques to isolate lateral hypothalamic afferents of the VTA in an optical ICSS paradigm, we have provided a level of anatomical specificity unachievable with conventional electrophysiological techniques. Although collision 
studies have suggested that myelinated fibers from the LH release glutamate onto dopamine neurons to promote their activity (Shizgal et al., 1980), it has never been definitively shown that stimulation of this direct pathway promotes intracranial selfstimulation in the VTA. Previous studies have described bidirectional modulation between NT and dopamine (Jomphe et al., 2006); however, this is the first study to establish that the lateral hypothalamic peptide enhances synaptic transmission in the VTA and promotes reward. Specifically, LH to VTA optical activation promotes NT and glutamate release in the VTA, and binding at Nts1 potentiates NMDA receptor activity, a critical component of optical ICSS behavior.

Numerous studies implicate other lateral hypothalamic peptides, such as hypocretin, $\mathrm{MCH}$, and CART in reward-related behaviors (DiLeone et al., 2003; Harris et al., 2005; Borgland et al., 2006). With the addition of NT to this group of reinforcing peptides, one must ask what purpose is served by multiple reward peptides in the LH to VTA pathway. Given the neuronal heterogeneity in the lateral hypothalamus, it is possible that the discriminating responses of the various peptide groups to peripheral signals may confer relative importance of physiological demands, such as delaying foraging to escape from a predator. When injected intracerebroventricularly, NT and hypocretin are anorectic and orexigenic, respectively (Luttinger et al., 1982; Haynes et al., 1999); however, both reinforce reward when endogenously released in the VTA (Felszeghy et al., 2007; Borgland et al., 2006). This dichotomy may enable animals in varied metabolic states to produce the behavioral response appropriate for the associated physiological demand. Studies investigating the relative ability of lateral hypothalamic peptides to modulate VTA dopamine neurons would be a beneficial avenue of research.

Given the behavioral importance of Nts1 and NMDA receptors in LH-to-VTA ICSS, we used whole-cell patch-clamp electrophysiology to test the effect of NT on excitatory transmission onto VTA dopamine neurons. Specifically, we have demonstrated that Nts1 activation potentiated NMDA-mediated currents in VTA dopamine neurons. At positive potentials where NMDA receptors are activated $(+40 \mathrm{mV})$, the NT-induced NMDA potentiation outweighed a small AMPA reduction, a form of inhibition that may protect against overexcitation. Measurement of EPSCs at a time point comprised of both NMDAand AMPA-mediated currents showed overall enhancement, although not as great as the current carried solely by NMDA receptors at the late phase of the EPSCs at $40 \mathrm{mV}$. Cells reach these positive potentials during every action potential, underscoring the high susceptibility of VTA dopamine neurons to NT enhancement during neuronal activation.

The effect of NT in the slice preparation occurred on the order of minutes, highlighting the temporal limitations of ex vivo experiments. This delay may be attributed to the time required for pharmacological penetration of the tissue or to the evenly paced $0.1 \mathrm{~Hz}$ stimulation protocol that produces reliable synaptic responses but does not replicate endogenous synaptic input. The NT-induced enhancement of NMDA-mediated EPSCs may result from mobilization and accumulation of intracellular calcium via Nts1 activation paired with glutamatergic excitation. Accordingly, one would predict that low-frequency ex vivo stimulation would produce a longer time
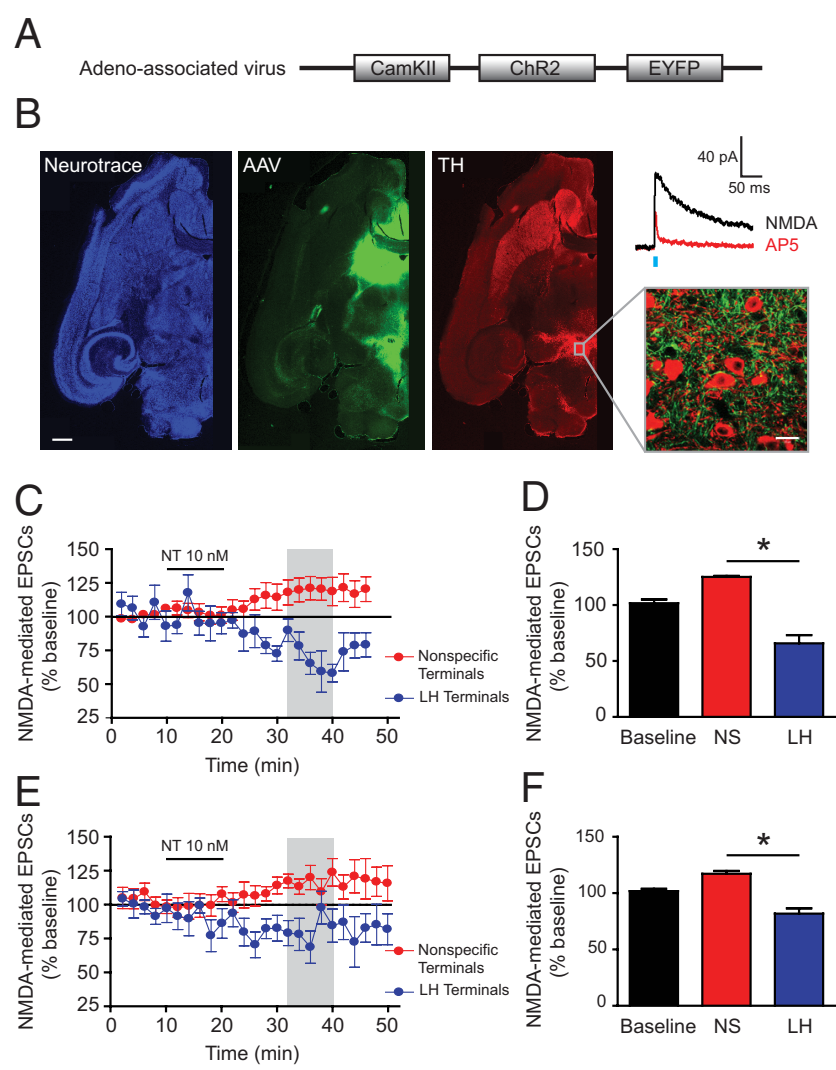

Figure 8. A, A graphic representation of the AAV construct: ChR2 and EYFP cassettes are under control of the (aMKII promoter. $\boldsymbol{B}$, Horizontal hemisection of mouse brain $(50 \mu \mathrm{m})$ : rostral is at the top of image; midline is along the right side. Neurotrace (blue) was used to visualize background tissue. AAV-induced ChR2-EYFP signal is shown in green (no antibody). TH antibody was visualized on the red channel to highlight dopamine neurons. Scale bar, $500 \mu \mathrm{m}$. Inset, VTA dopamine neurons surrounded by ChR2-expressing terminals. Scale bar, $20 \mu \mathrm{m}$. Example trace shows the NMDA current optically evoked by aiming a fiber optic directly at the recorded neuron in the VTA and the AMPA current measured in the presence of NMDA antagonist, AP5. Blue bar represents 5 ms flash of blue light. $C, D$, Comparison of electrically evoked EPSCs (nonspecific, NS) versus EPSCs evoked by optically stimulating LH to VTA fibers. Recordings were performed in separate experiments; however, electrical and optical stimulation was delivered at $0.1 \mathrm{~Hz}$ each. Nonspecific terminal stimulation: $119.2 \pm 1.3 \%, n=6$; L L terminal stimulation: $70.1 \pm 6.1 \%, n=6(p<$ 0.001). Analysis was conducted between minutes 32 and 40 in $\mathbf{C} \boldsymbol{F}$ as indicated by shaded regions. $\boldsymbol{E}, \boldsymbol{F}$, The experiment shown in $\boldsymbol{C}$ and $\boldsymbol{D}$ was repeated by recording alternating electrical and optical responses in the same cell. Each neuron received $0.1 \mathrm{~Hz}$ stimulation however, every other pulse was delivered by a bipolar stimulating electrode or a fiber optic coupled to a laser, such that each method of stimulation was delivered at $0.05 \mathrm{~Hz}$. Nonspecific terminal stimulation: $117.1 \pm 5.6 \%$; LH terminal stimulation: $81.8 \pm 4.8 \%$, $n=8(p<0.001)$.
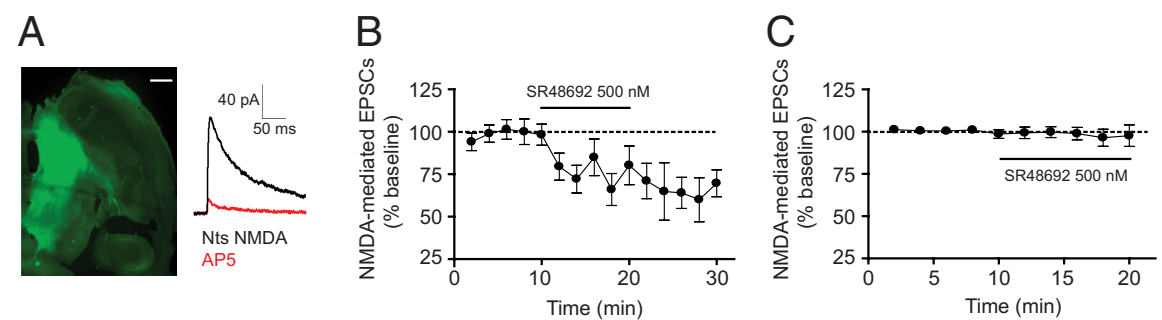

Figure 9. A, A hemisection of a horizontal mouse brain section used for recording the effect of NT-containing LH terminal activation in the VTA. Scale bar, $500 \mu \mathrm{m}$. NT-containing neurons in the LH were selectively infected with ChR2 via the Cre-lox system in mice. A double-floxed ChR2 virus was injected into the LH of Nts-Cre mice. Optical stimulation of LH neurotensincontaining axon terminals in the VTA produced NMDA currents (black) and AMPA currents (red). B, Nts1 antagonist, SR48692, reduced optically evoked NMDA currents to $67.2 \pm 4.5 \%(n=6, p<0.001)$. C, SR48692 did not significantly reduce electrically evoked NMDA currents $(98.4 \pm 1.4 \%, n=9, p=0.963)$. 
scale NT effect than would endogenous synaptic activation during an operant task. Although the exact temporal patterns of synaptic stimulation and in vivo neuropeptide release cannot be precisely reproduced ex vivo, the power of this technique lies in the ability to pharmacologically manipulate and measure synaptic transmission at isolated, subtype-defined synapses. NMDA receptor signaling is necessary and sufficient for burst firing in the VTA (Zweifel et al., 2008). Therefore, dopamine neuron bursting is a potential mechanism by which NT, via augmented NMDA receptor activity, promoted the VTA neuron excitation needed to elicit robust optical ICSS.

Interestingly, NT modulation of glutamate signaling in the VTA was not solely excitatory. At higher concentrations (100$500 \mathrm{nM}$ ), NT reduced the excitatory current mediated by NMDA and AMPA receptors. Experiments conducted in the absence of Nts1 signaling, both via pharmacological blockade and in NT receptor 1 knock-out mice, demonstrated that NT-induced synaptic depression was not Nts1-dependent. The Nts2 receptor is found presynaptically in the VTA (Binder et al., 2001), has a lower binding affinity than Nts1 (Mazella et al., 1996; Vincent et al., 1999), and is not excitatory when expressed in Chinese hamster ovary cell lines (Yamada et al., 1998). Given that NT reduced both AMPA- and NMDA-mediated currents at high concentrations, it is possible that presynaptic binding at Nts2 exerts inhibitory action similar to an autoreceptor. Indeed, brain regions, such as the prefrontal cortex that contain Nts1 and lack Nts2, have been linked to NT-induced glutamate excitotoxicity (Antonelli et al., 2004). Although it cannot be ruled out that higher doses of NT activate targets other than NT receptors, the anatomical and functional evidence supports the hypothesis that actions of high NT concentrations are mediated by Nts2.

Excitatory fibers innervating VTA dopamine neurons arise from numerous brain regions; however, neural transmission at distinct synaptic subtypes cannot be dissected with electrical stimulation. As in our behavioral paradigm, we used optogenetic techniques to isolate LH to VTA synapses ex vivo. We identified the effect of Nts1 activity on synaptic transmission at LH to VTA synapses and compared EPSC amplitude changes with those recorded in nonspecific, electrical experiments to explore functional heterogeneity of excitatory VTA synapses. NT (10 nM) exerted an excitatory effect on electrically evoked NMDAmediated EPSCs but reduced optically evoked LH to VTA currents similarly to higher concentrations of NT.

To test the hypothesis that endogenous NT is released at LH to VTA synapses, we solely stimulated NT-containing LH neurons to maximize the ability to detect peptide release in a slice preparation. The Nts1 antagonist significantly reduced optically evoked NMDA-mediated current generated by LH fibers but did not alter electrically evoked, nonspecific NMDA EPSCs. This evidence is consistent with the hypothesis that optical stimulation of LH fibers promoted peptide release in the midbrain slice, contributing to the baseline NMDA-mediated current. This finding also warrants future behavioral and electrophysiological studies in the recently developed Nts-Cre mice.

The difficulty in demonstrating peptide release in electrical slice electrophysiology experiments may arise from the fact that conventional electrical stimulation is not selective for peptide subpopulations and may activate synapses devoid of the peptide of interest. This hypothesis is difficult to reconcile with the anatomically dense network of NT fibers innervating the VTA (Hökfelt et al., 1984). Another feasible explanation is that optogenetic techniques activate more diverse intracellular machinery than standard electrical methods. Indeed, ChR2 is a cation channel that permits calcium influx (Nagel et al., 2003) and may therefore increase intracellular calcium to levels that promote dense core vesicle release (Elhamdani et al., 2000). It is also possible that the inhibitory effect of the Nts1 antagonist on optogenetic glutamate release is indirect. However, this is unlikely given that: (1) the fiber optic only produced optical responses when aimed directly at the recorded neuron, indicating a small stimulation area; and (2) picrotoxin, a $\mathrm{GABA}_{\mathrm{A}}$ receptor antagonist, was present in all experiments. Nonetheless, given that NT is also expressed in a subset of GABAergic LH neurons (Leinninger et al., 2009), experiments investigating the effect of NT on inhibitory synaptic transmission in the VTA would be beneficial.

Operant learning paradigms model aspects of reward-seeking behavior in humans. Our studies suggest that NT is a key lateral hypothalamic peptide that directly mediates reward-related behavior by enhancing glutamate transmission in midbrain dopamine neurons. Here we demonstrate that SR48692, a smallmolecule, nonpeptide antagonist of the NT 1 receptor, can reduce excessive amounts of reinforced behavior while maintaining lower levels of stimulation-seeking. Therefore, the Nts1 antagonist is potentially beneficial as a therapeutic agent that can be used to reduce human forms of pathological reward-seeking, such as drug addiction.

\section{References}

Adamantidis A, de Lecea L (2008) Physiological arousal: a role for hypothalamic systems. Cell Mol Life Sci 65:1475-1488. CrossRef Medline

Adamantidis AR, Tsai HC, Boutrel B, Zhang F, Stuber GD, Budygin EA, Touriño C, Bonci A, Deisseroth K, de Lecea L (2011) Optogenetic interrogation of dopaminergic modulation of the multiple phases of rewardseeking behavior. J Neurosci 31:10829-10835. CrossRef Medline

Antonelli T, Ferraro L, Fuxe K, Finetti S, Fournier J, Tanganelli S, De Mattei M, Tomasini MC (2004) Neurotensin enhances endogenous extracellular glutamate levels in primary cultures of rat cortical neurons: involvement of neurotensin receptor in NMDA induced excitotoxicity. Cereb Cortex 14:466-473. CrossRef Medline

Argilli E, Sibley DR, Malenka RC, England PM, Bonci A (2008) Mechanism and time course of cocaine-induced long-term potentiation in the ventral tegmental area. J Neurosci 28:9092-9100. CrossRef Medline

Binder EB, Kinkead B, Owens MJ, Nemeroff CB (2001) Neurotensin and dopamine interactions. Pharmacol Rev 53:453-486. Medline

Bonci A, Malenka RC (1999) Properties and plasticity of excitatory synapses on dopaminergic and GABAergic cells in the ventral tegmental area. J Neurosci 19:3723-3730. Medline

Borgland SL, Malenka RC, Bonci A (2004) Acute and chronic cocaineinduced potentiation of synaptic strength in the ventral tegmental area: electrophysiological and behavioral correlated in individual rats. J Neurosci 24:7482-7490. CrossRef Medline

Borgland SL, Taha SA, Sarti F, Fields HL, Bonci A (2006) Orexin A in the VTA is critical for the induction of synaptic plasticity and behavioral sensitization to cocaine. Neuron 49:589-601. CrossRef Medline

Bowers MS, Chen BT, Bonci A (2010) AMPA receptor synaptic plasticity induced by psychostimulants: the past, present and therapeutic future. Neuron 67:11-24. CrossRef Medline

Cáceda R, Kinkead B, Owens MJ, Nemeroff CB (2005) Virally mediated increased neurotensin 1 receptor in the nucleus accumbens decreases behavioral effects of mesolimbic system activation. J Neurosci 25:1174811756. CrossRef Medline

Carraway R, Leeman SE (1973) The isolation of a new hypotensive peptide, neurotensin, from bovine hypothalami. J Biol Chem 248:6854-6861. Medline

Chen BT, Bowers MS, Martin M, Hopf FW, Guillory AM, Carelli RM, Chou JK, Bonci A (2008) Cocaine but not natural reward self-administration nor passive cocaine infusion produces persistent LTP in the VTA. Neuron 59:288-297. CrossRef Medline

Chen L, Yung KK, Yung WH (2006) Neurotensin selectively facilitates glutamatergic transmission in globus pallidus. Neurosci 141:1871-1878. CrossRef Medline

DiLeone RJ, Georgescu D, Nestler EJ (2003) Lateral hypothalamic neuro- 
peptides in reward and drug addiction. Life Sci 73:759-768. CrossRef Medline

Elhamdani A, Brown ME, Artalejo CR, Palfrey HC (2000) Enhancement of the dense-core vesicle secretory cycle by glucocorticoid differentiation of PC12 cells: characteristics of rapid exocytosis and endocytosis. J Neurosci 20:2495-2503. Medline

Elliott PJ, Nemeroff CB (1986) Repeated neurotensin administration in the ventral tegmental area: effects on baseline and D-amphetamine induced locomotor activity. Neurosci Lett 68:239-244. CrossRef Medline

Farkas RH, Chien PY, Nakajima S, Nakajima Y (1996) Properties of a slow nonselective cation conductance modulated by neurotensin and other neurotransmitters in midbrain dopaminergic neurons. J Neurophysiol 76:1968-1981. Medline

Felszeghy K, Espinosa JM, Scarna H, Bérod A, Rostène W, Pélaprat D (2007) Neurotensin receptor antagonist administered during cocaine withdrawal decreases locomotor sensitization and conditioned place preference. Neuropsychopharmacology 32:2601-2610. CrossRef Medline

Ferraro L, Tomasini MC, Siniscalchi A, Fuxe K, Tanganelli S, Antonelli T (2000) Neurotensin increases endogenous glutamate release in rat cortical slices. Life Sci 66:927-936. CrossRef Medline

Fields HL, Hjelmstad GO, Margolis EB, Nicola SM (2007) Ventral tegmental area neurons in learned appetitive behavior and positive reinforcement. Annu Rev Neurosci 30:289-316. CrossRef Medline

Gallistel CR, Gomita Y, Yadin E, Campbell KA (1985) Forebrain origins and terminations of the medial forebrain bundle metabolically activated by rewarding stimulation or by reward-blocking doses of pimozide. J Neurosci 5:1246-1261. Medline

Geisler S, Zahm DS (2006) Neurotensin afferents of the ventral tegmental area in the rat: [1] re-examination of their origins and [2] responses to acute psychostimulant and antipsychotic drug administration. Eur J Neurosci 24:116-134. CrossRef Medline

Geisler S, Derst C, Veh RW, Zahm DS (2007) Glutamatergic afferents of the ventral tegmental area in the rat. J Neurosci 27:5730-5743. CrossRef Medline

Glimcher PW, Giovino AA, Hoebel BG (1987) Neurotensin self-injection in the ventral tegmental area. Brain Res 403:147-150. CrossRef Medline

Harris GC, Wimmer M, Aston-Jones G (2005) A role for lateral hypothalamic orexin neurons in reward seeking. Nature 437:556-559. CrossRef Medline

Haynes AC, Jackson B, Overend P, Buckingham RE, Wilson S, Tadayyon M, Arch JR (1999) Effects of single and chronic intracerebroventricular administration of the orexins on feeding in the rat. Peptides 20:1099-1105. CrossRef Medline

Hökfelt T, Everitt BJ, Theodorsson-Norheim E, Goldstein M (1984) Occurrence of neurotensinlike immunoreactivity in subpopulations of hypothalamic, mesencephalic, and medullary catecholamine neurons. J Comp Neurol 222:543-559. CrossRef Medline

Johnson SW, North RA (1992) Opioids excite dopamine neurons by hyperpolarization of local interneurons. J Neurosci 12:483-488.

Jomphe C, Lemelin PL, Okano H, Kobayashi K, Trudeau LE (2006) Bidirectional regulation of dopamine D2 and neurotensin NTS1 receptors in dopamine neurons. Eur J Neurosci 24:2789-2800. CrossRef Medline

Kalivas PW, Taylor S (1985) Behavioral and neurochemical effect of daily injection with neurotensin into the ventral tegmental area. Brain Res 358:70-76. CrossRef Medline

Kauer JA (2004) Learning mechanisms in addiction synaptic plasticity in the ventral tegmental area as a result of exposure to drugs of abuse. Annu Rev Physiol 66:447-475. CrossRef Medline

Kelley AE, Baldo BA, Pratt WE, Will MJ (2005) Corticostrial-hypothalamic circuitry and food motivation: integration of energy, action and reward. Physiol Behav 86:773-795. CrossRef Medline

Lacey MG, Mercuri NB, North RA (1990) Actions of cocaine on rat dopaminergic neurones in vitro. Br J Pharmacol 99:731-735.

Leinninger GM, Jo YH, Leshan RL, Louis GW, Yang H, Barrera JG, Wilson H, Opland DM, Faouzi MA, Gong Y, Jones JC, Rhodes CJ, Chua S Jr, Diano S, Horvath TL, Seeley RJ, Becker JB, Münzberg H, Myers MG Jr (2009) Leptin acts via leptin receptor-expressing lateral hypothalamic neurons to modulate the mesolimbic dopamine system and suppress feeding. Cell Metab 10:89-98. CrossRef Medline

Lüscher C, Malenka RC (2011) Drug-evoked synaptic plasticity in addiction: from molecular changes to circuit remodeling. Neuron 69:650-663. CrossRef Medline
Luttinger D, King RA, Sheppard D, Strupp J, Nemeroff CB, Prange AJ Jr (1982) The effect of neurotensin on food consumption in the rat. Eur J Pharmacol 81:499-503. CrossRef Medline

Margolis EB, Lock H, Hjelmstad GO, Fields HL (2006) The ventral tegmental area revisited: is there an electrophysiological marker for dopaminergic neurons? J Physiol 577:907-924.

Margules DL, Olds J (1962) Identical "feeding" and "rewarding” systems in the lateral hypothalamus of rats. Science 135:374-375. CrossRef Medline

Mazella J, Botto JM, Guillemare E, Coppola T, Sarret P, Vincent JP (1996) Structure, functional expression, and cerebral localization of the levocabastine-sensitive neurotensin-neuromedin $\mathrm{N}$ receptor from the mouse brain. J Neurosci 16:5613-5620. Medline

Nagel G, Szellas T, Huhn W, Kateriya S, Adeishvili N, Berthold P, Ollig D, Hegemann P, Bamberg E (2003) Channelrhodopsin-2, a directly lightgated cation-selective membrane channel. Proc Natl Acad Sci U S A 100: 13940-13945. CrossRef Medline

Nestler EJ (2005) Is there a common molecular pathway for addiction? Nat Neurosci 8:1445-1449. CrossRef Medline

Olds J, Milner P (1954) Positive reinforcement produced by electrical stimulation of septal area and other regions of rat brain. J Comp Physiol Psychol 47:419-427. CrossRef Medline

Panayi F, Colussi-Mas J, Lambás-Señas L, Renaud B, Scarna H, Bérod A (2005) Endogenous neurotensin in the ventral tegmental area contributes to amphetamine behavioral sensitization. Neuropsychopharmacology 30:871-879. CrossRef Medline

Phillips PE, Stuber GD, Heien ML, Wightman RM, Carelli RM (2003) Subsecond dopamine release promotes cocaine seeking. Nature 422:614-618. CrossRef Medline

Pontieri FE, Tanda G, Di Chiara G (1995) Intravenous cocaine, morphine, and amphetamine preferentially increase extracellular dopamine in the "shell" as compared with the "core" of the rat nucleus accumbens. Proc Natl Acad Sci U S A 92:12304-12308. CrossRef Medline

Roberts DC, Koob GF (1982) Disruption of cocaine self-administration following 6-hydroxydopamine lesions of the ventral tegmental area in rats. Pharmacol Biochem Behav 17:901-904. CrossRef Medline

Robinson TE, Berridge KC (2001) Incentive-sensitization and addiction. Addiction 96:103-114. CrossRef Medline

Rompré PP, Bauco P (2006) Neurotensin receptor activation sensitizes to the locomotor stimulating effect of cocaine: a role for NMDA receptors. Brain Res 1085:77-86. CrossRef Medline

Self DW, Barnhart WJ, Lehman DA, Nestler EJ (1996) Opposite modulation of cocaine-seeking behavior by D1- and D2-like dopamine receptor agonists. Science 271:1586-1589. CrossRef Medline

Shizgal P, Bielajew C, Corbett D, Skelton R, Yeomans J (1980) Behavioral methods for inferring anatomical linkage between rewarding brain stimulation sites. J Comp Physiol Psychol 94:227-237. CrossRef Medline

Sotty F, Soulière F, Brun P, Chouvet G, Steinberg R, Soubrié P, Renaud B, Suaud-Chagny MF (1998) Differential effects of neurotensin on dopamine release in the caudal and rostral nucleus accumbens: a combined in vivo electrochemical and electrophysiological study. Neuroscience 85 : 1173-1182. CrossRef Medline

Stuber GD, Sparta DR, Stamatakis AM, van Leeuwen WA, Hardjoprajitno JE, Cho S, Tye KM, Kempadoo KA, Zhang F, Deisseroth K, Bonci A (2011) Excitatory transmission from the amygdala to nucleus accumbens facilitates reward seeking. Nature 475:377-380. CrossRef Medline

Ungless MA, Whistler JL, Malenka RC, Bonci A (2001) Single cocaine exposure in vivo induces long-term potentiation in dopamine neurons. Nature 411:583-587. CrossRef Medline

Vincent JP, Mazella J, Kitabgi P (1999) Neurotensin and neurotensin receptors. Trends Pharmacol Sci 20:302-309. CrossRef Medline

Wanat MJ, Hopf FW, Stuber GD, Phillips PE, Bonci A (2008) Corticotropin-releasing factor increases mouse ventral tegmental area dopamine neuron firing through a protein kinase $\mathrm{C}$-dependent enhancement of Ih. J Physiol 586:2157-2170. CrossRef Medline

Wise RA (2006) Role of brain dopamine in food reward and reinforcement. Philos Trans R Soc Lond B Biol Sci 361:1149-1158. CrossRef Medline

Yamada M, Yamada M, Lombet A, Forgez P, Rostène W (1998) Distinct functional characteristics of levocabastine sensitive rat neurotensin NT2 receptor expressed in Chinese hamster ovary cells. Life Sci 62:375-380. CrossRef Medline

You ZB, Chen YQ, Wise RA (2001) Dopamine and glutamate release in the nucleus accumbens and ventral tegmental area of rat following lateral 
hypothalamic self-stimulation. Neuroscience 107:629-639. CrossRef Medline

Zahm DS, Grosu S, Williams EA, Qin S, Bérod A (2001) Neurons of origin of the neurotensinergic plexus enmeshing the ventral tegmental area in rat: retrograde labeling and in situ hybridization combined. Neuroscience 104:841-851. CrossRef Medline
Zweifel LS, Argilli E, Bonci A, Palmiter RD (2008) Role of NMDA receptors in dopamine neurons for plasticity and addictive behaviors. Neuron 59: 486-496. CrossRef Medline 